\title{
The time is right for Web-based clinical simulation in nursing education
}

\author{
Robyn P. Cant ${ }^{* 1}$, Simon J. Cooper ${ }^{2,3,4}$ \\ ${ }^{1}$ School of Nursing and Midwifery, Monash University, Berwick, Vic, Australia \\ ${ }^{2}$ School of Nursing, Midwifery and Healthcare, Federation University, Churchill, Vic, Australia \\ ${ }^{3}$ School of Nursing, The University of Hong Kong, Hong Kong \\ ${ }^{4}$ School of Nursing and Midwifery, University of Brighton, United Kingdom
}

Received: May 8, 2015

DOI: $10.5430 /$ jnep.v5n11p113
Accepted: July 19, 2015

Online Published: August 26, 2015

URL: http://dx.doi.org/10.5430/jnep.v5n11p113

\begin{abstract}
E-simulation involves goal-based role play using digital simulations that take place via a computer screen. Learners interact with the program via multi-media applications such as animation and video, graphics, sound, vision, and text through the use of advanced Web authoring tools. When the simulation is Web-based (via a remote server), this allows data collection and real-time feedback. We aimed to explore how the Internet has been utilized for the purposes of e-simulation in healthcare education. We describe published resources focusing on pre-registration education for undergraduate nursing and medicine students. Many studies in these domains have developed e-simulation as components of research, but we identified only four that were openly accessible (without fees). We describe four Web-based simulation programs that will benefit learners through better understanding of cardiopulmonary resuscitation; patient deterioration recognition and management; communication with the mentally ill; and knowledge of cultural competence. These programs have the advantage of being available across borders and are accessible to a broad audience wherever there is adequate Internet access. The approach appears to be highly acceptable to learners and offers the opportunity for repeated practice. The time is right for greater distribution and sharing of Web-based simulation resources for teaching in both undergraduate and at professional levels. Web-based simulation programs are a valuable resource that can be used in combination with traditional forms of laboratory and classroom teaching, in order to facilitate the development of students' clinical competence.
\end{abstract}

Key Words: Clinical simulation, Simulation education, Nursing, Virtual learning environments

\section{INTRODUCTION}

Evidence accumulated over the last decade supports the use of the simulated learning environment (SLE) as an effective teaching strategy in healthcare education. ${ }^{[1]}$ The SLE aims to replicate real life in a ward-like environment. Simulation studies describe this as a safe and controlled learning environment that can improve students' knowledge, skills, critical thinking, and/or their competence or confidence. ${ }^{[1-7]}$
Learning during simulation is also influenced by fidelity: the extent to which a simulation experience is perceived as real-world by the learner.

One driver of the increasing use of SLEs internationally is an escalation in the number of healthcare students who require clinical placement experience, especially in medicine and in nursing. In nursing, simulation education may replace a proportion of hours of clinical practice ${ }^{[8]}$ and many forms

\footnotetext{
*Correspondence: Robyn P. Cant; Email: robyn.cant@monash.edu; Address: School of Nursing and Midwifery, Monash University, PO Box 1071,
} Narre Warren, Vic, 3805, Australia. 
of simulation now make up curricula. ${ }^{[5]}$ To date, simulation approaches have predominantly been face-to-face, with learners participating individually or in groups in laboratorybased settings with simulated human patients, or manikins. Internationally, investment in simulation laboratories and the required technical equipment (such as task trainers, computerized whole-body mannequins) and staff training, has been substantial. This implies that simulation strategies will be used more commonly in disciplines such as nursing and medicine in the future.

Technology-enhanced simulation (e-simulation) is an emerging teaching and learning strategy that extends the reach of traditional face-to-face simulation in a laboratory (see Table 1). ${ }^{[9]}$ This is made possible through advances in information technology, faster Internet speeds, and increased accessibility for computer-based scholarly communication.

Table 1. E-simulation involves interactive learning

E-simulation:
Goal-based role-play using digital simulations that take place via a computer screen. Multi-media applications are used that can
include text, graphics, sound, vision, colour, animation and video. This type of program can be accessed via a DVD, CD-ROM or
local server- or on the Internet.
Web-based simulation:
An e-simulation program hosted on the Worldwide Web. This has potential for greater interactivity, as Web authoring tools allow
data collection through recording of mouse "clicks". Real-time feedback can be given to the learner about their action choices and
test scores/outcomes.

In this paper, we explore how the Internet has been utilized for the purposes of e-simulation in healthcare education. In particular, we describe published resources focusing on pre-registration education for undergraduate nursing and/or medicine students - as the majority of simulation research is known to be conducted in these domains. ${ }^{[1,10,11]}$ Multiple searches were made of healthcare databases to February 2015-which revealed very little research. Web-based simulation and e-simulation are very uncommon terms in the scholarly literature and interactive programs in these categories were only identified from collegial links with academics, searches of reference lists of medical and nursing publications, and through searches of Google and via ResearchGate database. We decided to use a narrative style to describe the limited findings. We answer the question: "Is the time right for Web-based simulation?" - with the inference that Web-based simulation could be an effective contemporary approach to healthcare education when resources are shared.

\subsection{Defining e-simulation}

E-simulation involves learners in goal-based role-play using digital simulations that take place via a computer screen. ${ }^{[12]}$ (see Figure 1a).

These programs depict real-life clinical case situations to engage the learner in problem-solving. They rely on various electronic media sources such as a DVD, a local server ( $e g$., on a university network), or a stand-alone website (Webbased simulation). Although many computer-mediated communication approaches have been developed and are used in education (eg., podcasts, blogs, discussion boards, video- conferencing) e-simulation is more technologically demanding as it involves interactive simulation-based learning. ${ }^{[13]}$ The design of the programs is also highly specialized, using multi-media applications. These can include text, graphics, sound, vision, colour, animation and video and advanced Web authoring tools (see Figure 1b). ${ }^{[14]}$

\subsection{How learners learn via e-simulation}

Ideally, e-simulation programs include an authentically presented problem-solving scenario, involving reflection and feedback. ${ }^{[15]}$ The educational process requires critical thinking and clinical decision making, with choices selected from a sequential or a branching set of options for each care episode (interactivity) that lasts over a short period of time. Learners become actively engaged in processing the subject matter and can achieve deep, rather than surface, learning. ${ }^{[16]}$ A key part of this trajectory is provided through individual feedback about actions taken (which is provided on-screen), enabled by real-time data collected from the learner's computer. This two-way communication (whether it be verbal or written), is the second way that e-simulation can be "interactive". Advantages and disadvantages of e-simulation are summarized in Table 2. As is the case with laboratory-based simulation, problem-solving through e-simulation can assist with the transfer of theoretical knowledge into the practice setting. ${ }^{[17]}$ E-simulation also has an added benefit in that learners complete the program in their own time and unobserved, potentially improving learning outcomes by reducing their anxiety state. ${ }^{[10]}$ In addition, e-simulation allows repeated practice, as there are no logistical concerns such as laboratory bookings, equipment or staff allocation. 
Table 2. Advantages and disadvantages of e-simulation for learning $\dagger$

\begin{tabular}{|l|l|}
\hline & Interactive, stimulating and enjoyable for learners \\
& Single-user or team interactions \\
& Provide realistic or real-world scenarios \\
Advantages of e-simulation & Enable controlled and predictable outcomes \\
& Promote trial-and-error learning in a risk-free setting \\
& Reduce face-to-face time and teaching resources \\
& Controlled access (through passwords) with feedback \\
& Wide availability. \\
& Can be expensive and time-consuming to build \\
& Often context and discipline specific \\
Disadvantages of e-simulation & May require extensive technical skills \\
& Potential for loss in speed through network traffic \\
& Vulnerable to security issues. \\
\hline
\end{tabular}

† Reprinted with permission from: Cant $\&$ Cooper ${ }^{[2]}$
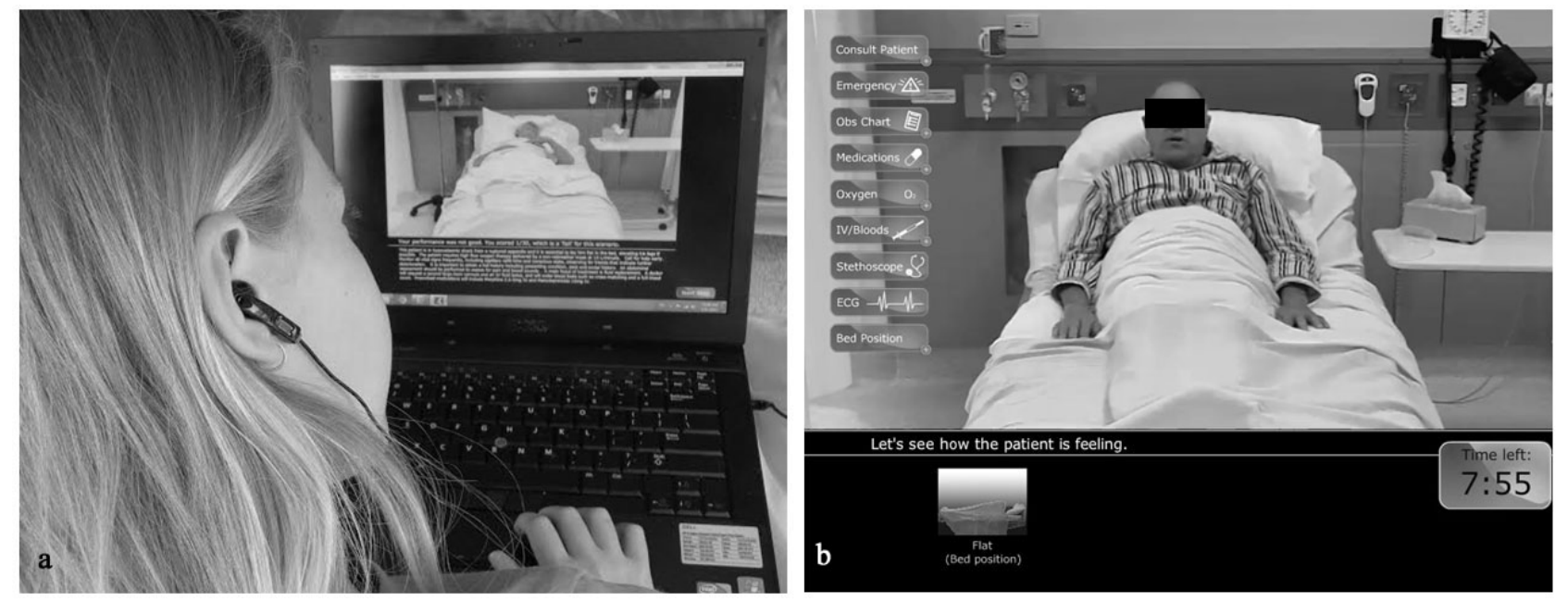

Figure 1. Screen shots: First ${ }^{\mathrm{TM}}$ Act Web patient deterioration program (reproduced with permission: Cooper et al.); ${ }^{[21]}$ a: FIRST $^{2} \mathrm{ACTWeb}^{\mathrm{TM}}$ an online interactive e-simulation education program; b: Screen shot of FIRST ${ }^{2} \mathrm{ACTWeb}^{\mathrm{TM}}$ main screen with optional intervention tabs and timer at 7 mins 55 seconds and counting down to zero

\section{Results}

Few Web-based simulation programs for nursing or medicine students hosted via the Internet are an open source. We identified four interactive and open access programs from a broad search of healthcare databases, publications, and the worldwide web.

A number of researchers in nursing have developed and evaluated additional in-house Web-based simulation programs ${ }^{[12]}$ however, these have not generally been hosted on an open platform allowing public access. In medicine, the Medibiquitous Consortium ${ }^{[18]}$ developed standards for using virtual patients (VPs) in videoed interactive case studies. From this web source some case studies were identified, but since access is limited to subscribers, we were unable to determine any program details. Also in medicine, there are computerbased simulations of surgical procedures using haptic devices Published by Sciedu Press and 3-D virtual models, enabling students to mimic technical procedures. As these programs are developed by academic researchers or commercial entities, none are open access.

Additional programs exist on commercial subscription sites. The high complexity of instructional design and the accompanying evaluation process means that programs are most often hosted on proprietary platforms with an access cost. Pay-as-you-go examples include Swift River Online Learning Systems (http: //swiftriveronline.com /) and Shadow Health (http: //www . shadowhealth. com). A number of platforms host collaborative virtual learning environments (computer-based virtual spaces or set of spaces): ${ }^{[19]}$ such as Open Sim (http://opensimulator. org) and Second life (http://secondlife.org). These platforms are available to institutions to develop web-based scenarios for individual and collaborative interactive learn- 
ing.

We describe below, four Web-based simulation and casebased open access programs that were located. These may be valuable as an adjunct to the clinical teaching of undergraduate nursing or medicine students.

\subsection{Cardiopulmonary resuscitation}

E-simulation is the basis for several programs in cardiopulmonary resuscitation available online from the American Heart Association $^{[20]}$ and other national heart associations. The HeartCode ${ }^{\circledR}$ BLS (http://www.heart.org/) is a self-directed, comprehensive interactive e-learning program for teaching students basic life support in a non-classroom setting. A set of written materials and two video tutorials, together with 14 interactive videoed e-simulations (using patient actors) are followed by debriefing notes and advice regarding corrective actions (using a voice-activated manikin). The scenarios depict adults or children. Completion requires timed clinical decisions from multiple on-screen options and participation in debriefing after each simulation. The program covers current standards, supplemented by a manual and certificate of completion. The tutorials take 1-2 hours to complete and the duration of the remainder (scenarios) will be variable. In general, students will need to access such programs via their educational institution.

\subsection{Hospital patient deterioration}

The authors of the current paper, as part of a larger team, developed and evaluated a multi-media Web-based simulation education program which aimed to develop nursing students' management of deteriorating patients. ${ }^{[17]}$ The program, funded by a grant from the Australian Government, is freely available for public access at: http://first2actw eb.com/. Participation takes approximately one and a half hours.

In the primary evaluation of this resource, final year nursing students $(\mathrm{n}=367)$ completed three on-line videoed interactive scenarios (with a patient actor). These depict acute myocardial infarction, chronic obstructive airways disease, and shock. ${ }^{[12]}$ Each featured stepwise cascading patientassessment and treatment options. Through "pop up" videos, students can view the patient's history, record an ECG, listen to breath sounds and give oxygen, or a selection of medications. Participants are able to prioritise their decisions over each of three 8-minute scenarios. Individual performance data are collected throughout (via click-streamed data) and summary ratings are provided at the end of each scenario with generic performance feedback. Educational outcomes were positive with clinical knowledge improving significantly at post-test $(p<.001)$, and skills performance improving be- tween the first and last scenario $(p<.001)$. Participants reported the program was realistic, with enhancements to competence and confidence $(p<.001)$. Although developed for nursing students, the program is being utilized internationally by all healthcare professional groups with approximately 6000 completions in the last 18 months (to March 2015).

\subsection{Communicating with the mentally ill}

An e-simulation mental health management program was designed for general nurses in NSW, Australia. ${ }^{[22]}$ This online open access three-part interactive clinical case scenario is based on a patient's psychological and emotional behaviour (see Figure 2). Key ideas or definitions are colour-coded for emphasis, with pop-up definitions available. As an engagment strategy, anxiety, tension and humour are incorporated. The program aims to show authentic representation and active participation, with strategies such as repetition, evaluation, and reflection to enhance retention. Supplementary resources are available. A limited qualitative evaluation identified that participants found the program engaging, realistic, and within their scope of practice. ${ }^{[23]}$ The resources are publicly available at: http: //inkysmudge.com.au/eSimulation/mhl.html).

\subsection{Learning cultural competence}

E-simulation is also the strategy used to advance the cultural competence of healthcare staff in a culturally diverse region of Sydney, Australia. An e-simulation program titled: Communicating with patients from culturally and linguistically diverse backgrounds, case study: Ms Shu Fen Chen, was developed and positively evaluated by 60 nurses and allied heath staff. ${ }^{[24]}$

As the engagement of learners is dependant on the authenticity of case scenarios, the research team selected a clinical context (chest pain) and cultural variation (Chinese culture) which was consistent with local conditions. Patient actors including an actor "interpreter" were used in the videoed scenario. Throughout development, authenticity and participation of the learner through use of repetition, evaluation, and reflection, were paramount. The program can be completed in around 60 minutes. The e-simulation program is freely available at: http://www. inkysmudge.com.au/el earning/chen and also as a CD ROM (see Figure 3).

\section{IMPLICATIONS FOR CLINICAL TEACHING}

Web-based simulation is a developing field of health professional education which has been limited by the financial and technical resources needed for program development. ${ }^{[12]}$ As a relatively new teaching resource, this type of simulation is yet to accumulate a comprehensive body of evidence of its effectiveness for learning. 


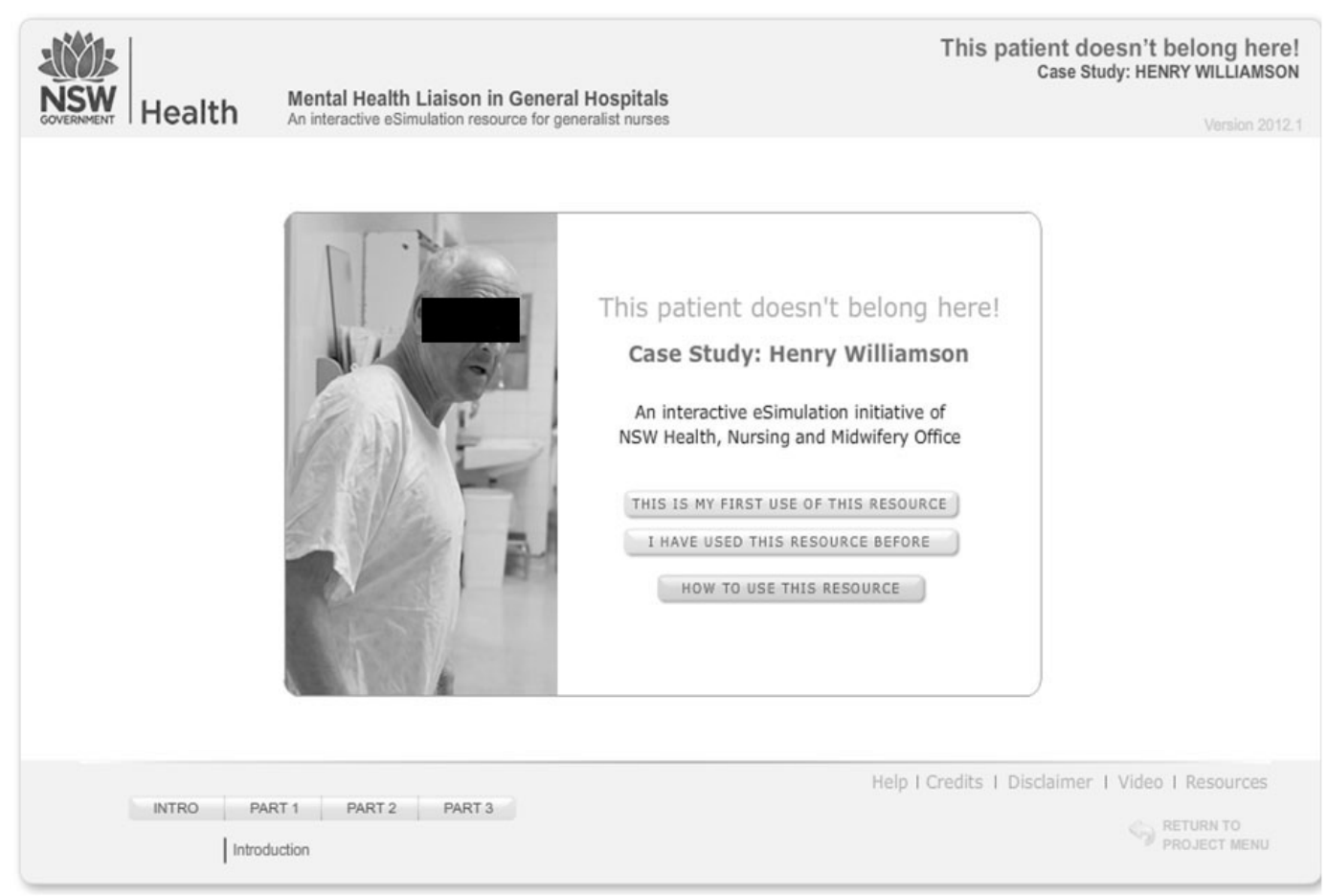

Figure 2. Mental Health Management- Screen shot of experienced actor and navigational menu (reproduced with permission from NSW Health and Lamont \& Brunaro $)^{[22]}$
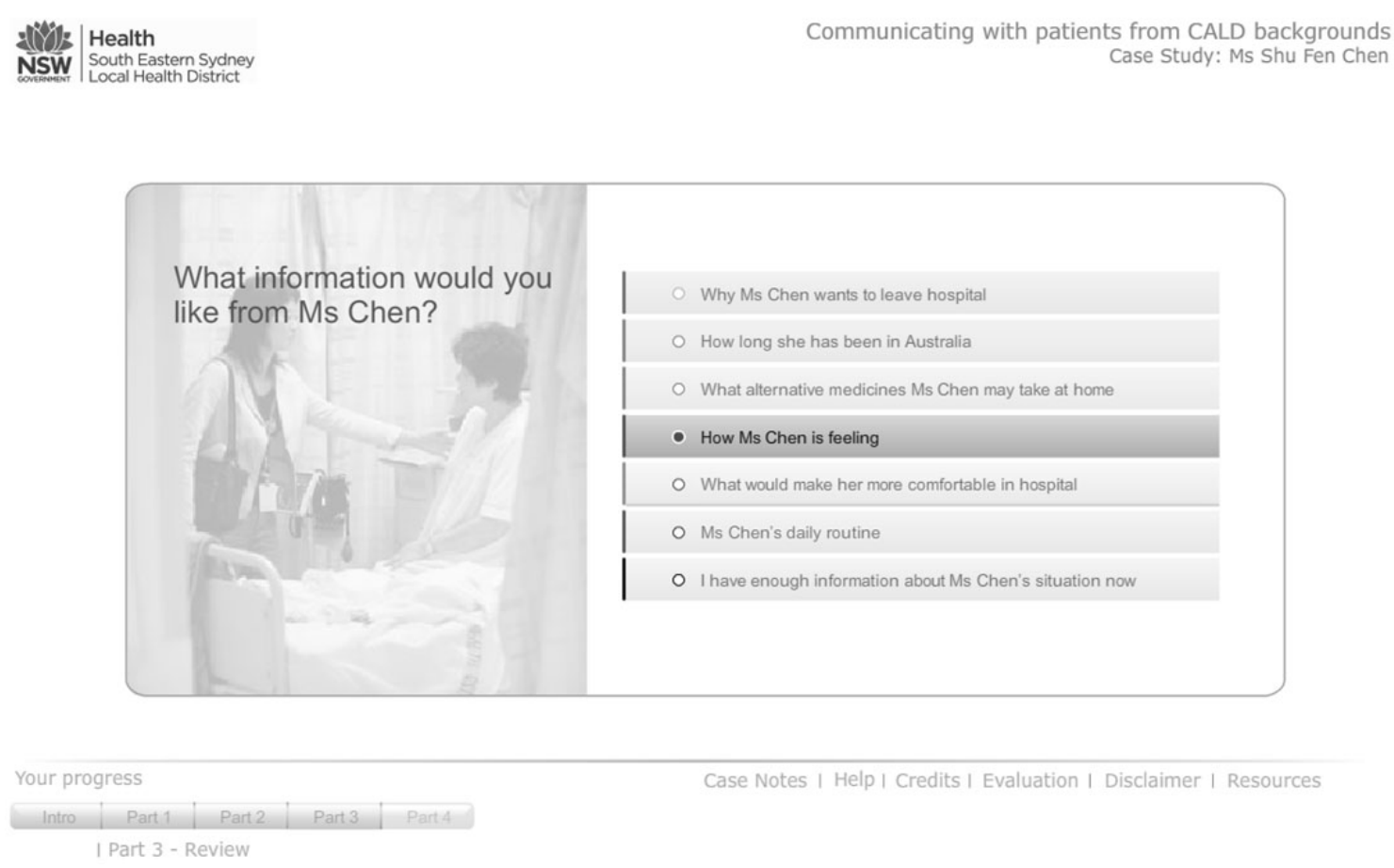

Figure 3. Cultural competence- Screen shot and navigational menu (reproduced with permission from NSW Health and Perry et al. $)^{[24]}$

Some studies of e-simulation (with programs based either locally on a personal computer, or on the worldwide web) have been shown to be largely as effective as other teaching meth-

Published by Sciedu Press ods in teaching clinical skills. For example, a randomized controlled trial involving first-year nursing students in learning pre- and post-operative skills on a computer screen or 
in a skills laboratory had similar learning outcomes. ${ }^{[25]}$ The computer program involved multiple presentations and case studies, while the control group worked with manikins in a laboratory. At retest after two weeks, knowledge test scores and observational skills ratings were similar between groups. Other studies that have used mainly objective measures report that e-simulation approaches can improve skills such as hand-washing, ${ }^{[7]}$ electrocardiography, ${ }^{[26]}$ urinary catheterization, ${ }^{[27]}$ and identification/management of patient deterioration. ${ }^{[17]}$ The Web-based programs described earlier that reported an evaluation ${ }^{[17,23,24]}$ were also found to be acceptable to the targeted learners.

There are many stages involved in developing a multi-media Web-based application and in subsequently testing suitability and effectiveness with the target audience. ${ }^{[14,28]}$ Once developed, Web-based simulation programs are a substantial resource that have an advantage compared with other teaching modalities, of being available across borders. A program can be accessible to a broad audience, situated wherever there is adequate Internet access. Furthermore, the approach appears to be highly acceptable to learners ${ }^{[10]}$ and provides opportunity for repeated practice at will. Thus, various schools or universities could utilize the same program with potential for resource savings and increased efficiencies. One limitation is that programs may have a limited life span for each edition; as clinical practice develops and there is a need for regular revisions of material.

Available studies in healthcare education suggest that e- learning should be used in combination with other forms of teaching such as traditional classroom methods, for nursing students to master clinical skills. ${ }^{[29]}$ E-simulation could be used in the curriculum to enhance clinical skills prior to a session using classroom teaching. In particular, with the recent focus on patient safety education, e-simulation appears to be suitable to develop skills and competencies in patient safety across the nursing curriculum. ${ }^{[30]}$

\section{Conclusion}

Many e-simulation programs have not been disseminated widely as, for example, institutions host programs on their Intranet or on subscription sites. While web-based simulation is clearly an important adjunct to clinical teaching, the lack of public access also limits development of more sophisticated programs in this field. Public funding agencies should consider supporting open access platforms for the longer term, thus enabling further development. The time is right for greater distribution and sharing of web-based simulation resources for teaching in both undergraduate and at professional levels. Web-based simulation programs are a valuable resource that should be used in combination with traditional forms of laboratory and classroom teaching in order to facilitate the development of students' clinical competence.

\section{CONFLICTS OF INTEREST DisClOSURE}

The authors declare that there is no conflict of interest.

\section{REFERENCES}

[1] Motola I, Devine LA, Chung HS, et al. Simulation in healthcare education: A best evidence practical guide. AMEE Guide No. 82 Med Teach. 2013; 35: e1511-e30. http://dx.doi.org/10.3109 /0142159X.2013.818632

[2] Secomb J, McKenna L, Smith C. The effectiveness of simulation activities on the cognitive abilities of undergraduate third-year nursing students: a randomised control trial. J Clin Nurs. 2012; 21: 3475-84 http://dx.doi.org/10.1111/j.1365-2702.2012.04257.x

[3] Weaver A. High-fidelity patient simulation in nursing education: An integrative review. Nurs Educ Perspect. 2011; 32: 37-40. http: //dx.doi.org/10.5480/1536-5026-32.1.37

[4] Lewis R. Strachan A, McKenzie SM. Is High fidelity simulation the most effective method for the development of non-technical skills in nursing? a review of the current evidence. The Open Nursing Journal 2012; 6: 82-9. http://dx.doi.org/10.2174/1874434601206 010082

[5] Cant R, Cooper S. Simulation-based learning in nurse education: systematic review. J Adv Nurs. 2009; 66: 3-15. http://dx.doi.o $\mathrm{rg} / 10.1111 / \mathrm{j} .1365-2648.2009 .05240 . \mathrm{x}$

[6] Yuan HB, Williams BA, Fang JB. The contribution of high-fidelity simulation to nursing students' confidence and competence: a sys- tematic review. Int Nurs Rev. 2014; 59: 26-33. http://dx.doi.o $\mathrm{rg} / 10.1111 / \mathrm{j} .1466-7657.2011 .00964 . \mathrm{x}$

[7] Bloomfield J, Roberts J, While A. The effect of computer-assisted learning versus conventional teaching methods on the acquisition and retention of handwashing theory and skills in pre-qualification nursing students: A randomised controlled trial. International J Nurs Stud. 2010; 47: 287-94. http://dx.doi.org/10.1016/j.ijnur stu. 2009.08.003

[8] Hope A, Garside J, Prescott S. Rethinking theory and practice: Preregistration student nurses experiences of simulation teaching and learning in the acquisition of clinical skills in preparation for practice. Nurse Educ Today. 2011; 31: 711-15. http://dx.doi .org/10.10 $16 / \mathrm{j}$. nedt .2010 .12 .011

[9] Cook D, Hatala R, Brydges R, et al. Technology-enhanced simulation for health professions education: a systematic review and meta-analysis. JAMA. 2011; 306: 978-88. PMid:21900138 http: //dx.doi.org/10.1001/jama.2011.1234

[10] Cant R, Young S, Porter J, et al. E-simulation: pre-registration nursing students' evaluation of an on-line patient deterioration program. Comput Inform Nurs. 2015; 3: 108-14. http://dx.doi.org/10. 1097/CIN. 0000000000000133 
[11] Cook D, Hatala R, Brydges R, et al. Technology-enhanced simulation for health professions education a systematic review and meta-analysis. JAMA. 2011; 306: 978-88. PMid:21900138 http: //dx.doi.org/10.1001/jama.2011.1234

[12] Cant R, Cooper SJ. Simulation in the Internet Age: The place of Web-based simulation in nursing education. An integrative review. Nurse Educ Today. 2014; 34: 1435-42. http://dx.doi.org/10. 1016/j.nedt. 2014.08.001

[13] Deakin University. Developing e-Simulations: module plan 002, in Virtual situated learning environments. Deakin University: Melbourne. 2013.

[14] Davids MR, Chikte UME, Halperin ML. Development and evaluation of a multimedia e-learning resource for electrolyte and acid-base disorders. Adv Physiol Educ. 2011; 35: 295-306. PMid:21908840 http://dx.doi.org/10.1152/advan.00127.2010

[15] Buykx P, Kinsman L, Cooper S, et al. FIRST2ACT: educating nurses to identify patient deterioration - a theory-based model for best practice simulation education. Nurse Educ Today. 2011; 31: 687-93. http://dx.doi.org/10.1016/j.nedt.2011.03.006

[16] Lasater K. High-fidelity simulation and the development of clinical judgment: Students' experiences. J Nurs Educ. 2007; 46: 269-76. PMid:17580739

[17] Cooper S, Cant R, Bogossian F, et al. Patient deterioration education: Evaluation of face-to-face simulation and e-simulation approaches. Clinical Simulation in Nursing. 2015; 11: 97-105. http://dx.doi.org/10.1016/j.ecns. 2014.10.010

[18] Medibiquitous Consortium. Virtual patient implementers. 2013. Available from: http://www.medbiq.org/virtual_patient/i mplementers

[19] Mavridis A, Konstantinidis A, Tsiatsos T. A comparison of 3D collaborative virtual learning environments: OpenSim vs Second Life. International Journal of e-Collaboration. 2012; 8: 8-21. http: //dx.doi.org/10.4018/jec. 2012100102

[20] American Heart Association. HeartCode BLS Part 1. 2013. Availablefrom: http://www.heart.org/HEARTORG/CPRAndECC /HealthcareProviders/BasicLifeSupportBLS/HeartCode reg-BLS-Part-1_UCM_303478_Article.jsp

[21] Cooper S, Porter J, Bogossian F, et al. Development and evaluation of a Web-based patient deterioration management program. [Final report] Australian Government Office of Learning and Teaching, Sydney, Australia. 2014.

[22] Lamont S, Brunero S. E-Simulation Part 1: Development of an interactive multimedia mental health education program for generalist nurses. Collegian. 2013; 20: 239-47. PMid:24596993 http: //dx.doi.org/10.1016/j.colegn.2012.11.001

[23] Lamont S, Brunero S. E-Simulation Part 2: Evaluation of an interactive multimedia mental health education program for generalist nurses. Collegian. 2013; 21: 3-9. http://dx.doi.org/10.1016 /j.colegn. 2012.11.002

[24] Perry A, Woodland L, Brunero S. eSimulation: A novel approach to enhancing cultural competence within a health care organisation. Nurs Educ Pract. 2015.

[25] Durmaz A, Dicle A, Cakan E, et al. Effect of screen-based computer simulation on knowledge and skill in nursing students' learning of preoperative and postoperative care management: A randomized controlled study. Comput Inform Nurs. 2012; 30: 196-203. http://dx .doi .org/10.1097/NCN . Ob013e3182419134

[26] Jang K, Hwang SY, Park SJ, et al. Effects of a Web-based teaching method on undergraduate nursing students' learning of electrocardiography. J Nurs Educ. 2005; 44: 35-9.

[27] Ozturk D, Dina L. Effect of web-based education on nursing students' urinary catheterization knowledge and skills. Nurse Educ Today. 2014; 34: 802-8. http://dx.doi.org/10.1016/j.nedt. 2013.08.007

[28] Zary N, Johnson G, Boberg J, et al. Development, implementation and pilot evaluation of a Web-based virtual patient case simulation environment - Web-SP. BMC Med Educ. 2006; 6: 10. PMid:16504041 http://dx.doi.org/10.1186/1472-6920-6-10

[29] Bloomfield JG, Jones A. Using e-learning to support clinical skills acquisition: Exploring the experiences and perceptions of graduate first-year pre-registration nursing students - A mixed method study. Nurse Educ Today. 2013; 33: 1605-11. http://dx.doi.org/10. $1016 / j$.nedt . 2013.01.024

[30] Berndt J. Patient safety and simulation in pre-licensure nursing education: An integrative review. Teaching and Learning in Nursing. 2014; 9: 16-22. http://dx.doi.org/10.1016/j.teln.2013.0 9.001 